\title{
Development of a Self-Assessment Questionnaire for Nurses' Risk-Taking Behavior in Medication
}

\author{
Yayoi Imura1, Chiharu Akazawa² \\ ${ }^{1}$ Faculty of Nursing, Shijonawate Gakuen University, Osaka, Japan \\ ${ }^{2}$ Faculty of Nursing, Osaka Medical and Pharmaceutical University, Osaka, Japan \\ Email: y-imura@un.shijonawate-gakuen.ac.jp
}

How to cite this paper: Imura, Y. and Akazawa, C. (2022) Development of a SelfAssessment Questionnaire for Nurses' RiskTaking Behavior in Medication. Health, 14, 1-22.

https://doi.org/10.4236/health.2022.141001

Received: December 14, 2021

Accepted: January 4, 2022

Published: January 7, 2022

Copyright $\odot 2022$ by author(s) and Scientific Research Publishing Inc. This work is licensed under the Creative Commons Attribution International License (CC BY 4.0).

http://creativecommons.org/licenses/by/4.0/

\section{(c) (i) Open Access}

\begin{abstract}
Purpose: The purpose of this study was to prepare a self-assessment questionnaire for nurses' risk-taking behavior (RTB) in medication and to develop a reliable and valid questionnaire. Method: In the first study, a draft of the self-evaluation questionnaire for nurses' RTB in medication was prepared based on the literature study and qualitative analysis of important case information included in the Project to Collect Medical Near-miss/Adverse Event Information Annual Report of the Ministry of Health, Labor and Welfare. Following the studies, face validity was confirmed, and a questionnaire survey was conducted for nurses who oversee medication nationwide to verify the reliability and validity. Result: The number of subjects was 586 (valid response rate: $94.1 \%)$. Item analysis and exploratory factor analysis showed that 4 factors and 12 items for the RTBs in daily life and 4 factors and 20 items for RTBs in medication could be extracted. Confirmatory factor analysis confirmed the fit of the hypothetical model obtained by exploratory factor analysis. In addition, Cronbach's a coefficient was 0.888 . Thus, high reliability and validity were obtained. A correlation was found by comparing the total scores of each RTB factor with the incident/accident group, and a standard for self-evaluation value could be established $(\mathrm{p}<0.01)$. Conclusions: We were able to develop a self-assessment questionnaire for nurses' risk-taking behavior in medication. This questionnaire will be used by nurses to find out their trends.
\end{abstract}

\section{Keywords}

Self-Assessment Questionnaire, Risk-Taking Behavior, Nurses, Medication

\section{Introduction}

In Japan, medical accidents are reported every year. According to the important 
case information revealed by Project to Collect Medical Near-miss/Adverse Event Information 2018 Annual Report, there were still 4565 medical accidents and 930,000 near-miss cases, and serious medical accidents also occurred [1]. Especially, many accidents related to drugs occurred, and about $60 \%$ of them involved nurses. In a medical setting, although medical safety measures with the highest priority have been taken centering on system improvement, many problems due to personal factors in the breakdown of medical accidents by factor are included.

Efforts to reduce medical accidents require preventive measures against both "system" and "personal" factors [2], but the current situation is that organizations and systems are mainly being addressed [3]. Therefore, it is necessary to take measures for "personal" factors, and we thought it necessary to take measures for personal risk-taking behavior, which is considered being one of the factors.

Risk-taking behavior (RTB) refers to behavior that is performed while recognizing the danger or possibility of damage to the subject. In addition, it includes behavior that does not recognize the danger or possibility of damage to the subject and behavior that involves uncertainty such as "maybe it is okay", and conscious and unconscious behaviors were noted in personal behaviors [4]. Thus, ambiguous behavior is considered to be one cause of medical accidents.

There are several scales for measuring personal RTBs, but the number is still small [5] [6].

Kosio has developed an RTB scale (RTBSU) for college students [7].

This scale deals with two factors (personal and social risk behaviors) and consists of 12 items, and its reliability is recognized. However, since the class participation rate and the daily life situation of university students are evaluated as scale scores, it can be applied only to university students.

Matsuzaki created a self-made questionnaire and surveyed concerning a list of risk behaviors to analyze the RTBs of nursing students [8]. He suggested that those who rate lower risks in daily life and higher probabilities of taking risktaking behaviors are more likely to take risks in a nursing setting. In addition, Fujii, who studied the influential factors of risk assessment in a nursing setting where falls are predicted, clarified that RTBs in traffic situations and daily situations and the risk-taking probability in a nursing setting have a strong influence as predictors. She also suggested that RTBs may not be taken if nurses receive a high mark for risk assessment in nursing practice [9].

Yoshida, who conducted a questionnaire survey on RTB-related factors, suggested that those with a high proportion of RTB in nursing practice, shorter years of experience, and weak internal control tend to take risks. However, the reliability and validity of the questionnaire were not clarified [4].

Adachi conducted a questionnaire survey using the scene assumption method to capture the human unsafe behavior on the theme of psychological causes of violations of nursing practice. She suggested that objective risk assessment and 
time and social pressures influence risk assessment [10]. In these nursing studies, it has been suggested that the tendency of an individual's daily life affects nursing practice as an RTB-related factor, but no scale for personal RTBs was found.

Outside of nursing, some questionnaires related to RTBs have been reported. Overseas, Weber created a questionnaire focusing on five areas of money, health and safety, entertainment, ethics, and society as a risk-taking scale in daily life, which was highly reliable and valid [11]. However, there are differences in culture and customs, so it was necessary to keep them in mind when using them. In Japan, Moriizumi developed an RTB scale with high reliability and validity. This can measure daily risk tendency and be composed of four factors: confident behavior, gambling orientation, safety considerations, and situational behavior, but it was not intended for some medical situations [12] [13].

Thus, the purpose of this study was to create a questionnaire that can be adapted to measure the tendency of nurses' RTBs in medication situations associated with many reports of medical accidents and to verify its reliability and validity.

\section{Purpose}

The purpose of this study was to develop a self-assessment questionnaire for nurses' RTBs on medication. To achieve this, we conduct a questionnaire survey of nurses nationwide and verify the obtained data by exploratory factor and confirmatory factor analyses.

\section{Definition of Terms}

Risk-taking behavior is behavior that is performed while recognizing the potential risk of the subject. Or, it includes conscious and unconscious behaviors when the potential risk to the subject is not recognized or when there is uncertainty that it is probably okay.

\section{Study Methods}

The following steps were taken to consider a reliable and valid questionnaire that could be adapted to measure nurses' RTB tendency in medication.

\subsection{Development Process of Question Items}

Figure 1 shows the development process of the question items in this study. In this study, we first created a questionnaire consisting of three parts of question items: attribute items, RTBs in daily life, and RTBs in medication.

The question items that ask the attributes of research collaborators included a total of 9 items: gender, age, years of experience as a nurse, years of experience at the assigned place, duty position, educational background, experience as a member of medical safety measures committee, and incident/accident experience. A five-point scale was used to answer these questions. Regarding RTBs in 
Development of a self-assessment questionnaire for nurses' risk-taking behavior in medication: flowchart

First study: Extraction of question items Literature review

Examination by text mining of medical accident report contents

Examination of surface validity by group interview

Second Study: Examination of validity and reliability by questionnaire survey

Exploratory factor analysis

Confirmatory factor analysis

Internal consistency based on Cronbach's a coefficient

Examination of self-evaluation criteria

Completion of the questionnaire

Figure 1. Development of a self-assessment questionnaire for nurses' risk-taking behavior in medication: flowchart.

daily life, 33 items were created concerning the question items based on the factors and research results clarified from the previous studies. Regarding RBTs in daily medication practice, accidents and near-miss reports due to nurses' risk-taking behaviors in medication included in the Project to Collect Medical Near-miss/Adverse Event Information Annual Report of the Japan Council for Quality Health Care were investigated. From more than 15,000 reports regarding medical accidents, 675 cases in which RTBs were recognized as the background factors of the accident were extracted, and 53 question items were created based on analyses using text mining for the contents of the reports [14].

Through these procedures, a questionnaire including a total of 95 items was created. A group interview was then conducted with four nurses who had more than 10 years of clinical experience and experience as a member of the medical safety measures committee to examine the face validity of the question items. As a result, duplicate items were deleted, contents and languages were unified, and 91 question items were finally completed [15].

A 5-point scale questionnaire (never: 1 point, rarely: 2 points, occasionally: 3 points, sometimes: 4 points, frequently: 5 points) was used for answering questions about RTBs in daily life concerning previous studies.

A 4-point scale questionnaire (never: 1 point, rarely: 2 points, sometimes: 3 points, frequently: 4 points) was used for answering questions about RTBs in medication by a nurse because some studies have reported that Japanese tend to select answers with median scores. Scoring was set so that the higher the tendency of RTBs, the higher the score [16].

\subsection{Survey Methods and Subjects}

Using the prepared questionnaire, we conducted an anonymous self-administered survey in nurses working in regional medical support hospitals (hospitals with 200 or more beds) and special function hospitals nationwide. The target hospitals were randomly selected concerning the materials of the Ministry of Health, Labor, and Welfare, and a request form describing a research explanation on the 
development of a self-assessment questionnaire for nurses' risk-taking behaviors in medication was mailed in writing to the director and the nursing department. We asked the nursing department of the hospitals that provided the consent to distribute a questionnaire to each research collaborator. The survey was conducted from April to August 2021.

\subsection{Statistical Analysis Methods}

SPSS $^{\circledast}$ Statistics V25 and IBM SPSS Amos 25 were used for response analysis, and response bias-prone analysis, peakedness/skewness tests, Good-Poor Analysis (hereinafter referred to as GP analysis), and Item-Total Correlation Analysis (hereinafter referred to as IT analysis) are performed according to the following procedures.

\section{1) Item analysis}

Descriptive statistics of the obtained responses were performed to calculate the attributes of the subjects. Response bias-prone analysis was then performed to see if there was a significant bias in each question item, and those with a ceiling effect (average $+1 \mathrm{SD}$ ) or floor effect (average $-1 \mathrm{SD}$ ) were excluded. Next, G-P analysis was performed. Based on the total score, subjects with higher and lower scores were divided into two groups, the average score of each item was calculated for each group, and the scores were compared. Only items that exhibited a significant inter-group difference in the average scores $(\mathrm{P}<0.05)$ were left, and the others were excluded.

The item-Total correlation was examined to see if the consistency among the question items and the reliability of the question items were maintained. Items with low correlation were excluded because they reduce reliability. Evaluation criteria to exclude items with low correlation were set to be correlating values of 0.20 or less, and items with low relevance and items that were not significant were also subjected to these criteria [17].

\section{2) Examination of construct validity}

Factor analysis was performed to confirm the factor structure of the questionnaire and select items. For the RTB items in daily life and the nurses' RTB items in medication, exploratory factor analysis was performed by using the maximum likelihood method and Promax rotation to verify the factorial validity of each item. In the factor analysis of the initial solution, the number of factors was determined based on the Kaiser-Guttman rule and the scree plot. In addition, items with a low commonality of 0.25 and items with a factor loading of less than 0.35 when an eigenvalue was set to be 1.0 or more for factors were deleted. After that, the number of factors was fixed, and factor analysis was repeated until the inter-factor items were established. Following these procedures, covariance structure analysis was used to examine the goodness of fit between the data and the model. Goodness of Fit Index (GFI), Adjusted Goodness of Fit Index (AGFI), Comparative Fit Index (CFI), and Root Mean Square Error of Approximation (RMSEA) were used to determine the goodness of fit. It is judged 
that the model fits better when the GFI, AGFI, and CFI values are closer to 1 and that the model data fits better when the RMSEA value is 0.05 or less. Then, for the factor items that could be extracted, the conformity of the model based on the multi-index of covariance structure analysis was examined for the convergent validity and the discriminant validity [18].

For the convergent validity, the relationship between each factor of RTBs and incident/accident experiences was examined. A causal model was created using the scores of each factor of RTBs in daily life and RTBs in medication as observation variables, and the tendencies of RTBs in daily life and RTBs in medication as latent variables. These latent variables and incidents/accidents as dependent variables were also analyzed to examine the goodness of fit between the data and the model.

In the examination of the discriminant validity, educational background, years of experience, and experience as a member of the medical safety measures committee were examined. In these examinations, items with different concepts were measured and predicted to be not due to the RTB tendency.

\section{3) Examination of the reliability}

The internal consistency of each sub-item of question items for RTBs in daily life and RTBs in medication by the nurse was examined. The internal consistency was verified by the reliability coefficient (Cronbach's $\alpha$ coefficient: 0.7 to 0.8 or more) of all the question items and each item.

4) Correlation between RTBs and incident/accident experiences in medication and examination of evaluation criteria

The relationship between RTBs in medication and medical accidents was predicted, and the relationship between the total RTB score and the incident/accident score was examined by calculating Pearson's correlation coefficient. Those with high RTB total scores were predicted to have high incident/accident scores. The total score of the extracted RTB was then divided into four equal groups and used as the dependent variables. Moreover, the independent variables were used as incident/accident experience and subjected to tests. Independent samples with differences between the four groups were analyzed by using the Kruskal-Wallis test and the significance level was set at $\mathrm{P}<0.01$.

\subsection{Ethical Considerations}

This study was conducted with the approval of the Institutional Review Board of Osaka Medical and Pharmaceutical University. After answering the questionnaire, the collaborators posted an anonymous reply using the enclosed reply envelope. Upon receiving the reply, it was considered that consent to participate in the research was obtained. The survey was a completely anonymous one and was conducted with due consideration for privacy protection so that no individual was identified, and information was not leaked.

\section{Results}

Questionnaires were distributed to nurses at 44 facilities that approved a survey 
requested, and 623 cases with anonymous replies were included in this study. Of these, 586 valid responses (valid response rate: $94.1 \%$ ) were subjected to the following analyses.

\subsection{Attribute Overview}

Forty-nine males and 537 females were included in this study. Nurses in the 20s were 310 , followed by 120 in the 30s, 107 in the 40 s, and 49 in the 50s. By years of experience, 156 nurses had 3 to 5 years of experience, 125 had 0 to 2 years of experience, and 281 (47.9\%) had up to 5 years of experience, showing that about half of nurses had up to 5 years of experience. In addition, regarding the number of years assigned to the current department, 322 nurses (55.1\%) had up to 2 years, $186(31.7 \%)$ had 3 to 5 years, showing that about $82 \%$ of nurses have been assigned to the current department. Regarding the incident experience, "occasionally" was the most frequent answer among 345 nurses (Table 1).

Table 1. Attributes of the subjects $(n=586)$.

\begin{tabular}{|c|c|c|}
\hline & & Headcount \\
\hline \multirow{2}{*}{ Gender } & Male & 49 \\
\hline & Female & 537 \\
\hline \multirow{4}{*}{ Age } & $20 s$ & 310 \\
\hline & $30 \mathrm{~s}$ & 120 \\
\hline & $40 \mathrm{~s}$ & 107 \\
\hline & $50 \mathrm{~s}$ & 49 \\
\hline \multirow{6}{*}{ Years of experience as a nurse, } & $0-2$ years & 125 \\
\hline & 3 - 5 years & 156 \\
\hline & $6-10$ years & 93 \\
\hline & $11-15$ years & 38 \\
\hline & $16-20$ years & 42 \\
\hline & 21 years- & 132 \\
\hline \multirow{5}{*}{ Years of experience at assigned place } & $0-2$ years & 323 \\
\hline & $3-5$ years & 186 \\
\hline & $6-10$ years & 65 \\
\hline & $11-15$ years & 6 \\
\hline & 16 years- & 6 \\
\hline \multirow{3}{*}{ Educational background } & Academy & 465 \\
\hline & University & 113 \\
\hline & Graduate school & 8 \\
\hline \multirow{5}{*}{ Incident experience } & Never & 7 \\
\hline & Rarely & 121 \\
\hline & Occasionally & 345 \\
\hline & Sometimes & 109 \\
\hline & Frequently & 4 \\
\hline \multirow{5}{*}{ Accident experience } & Never & 289 \\
\hline & Rarely & 211 \\
\hline & Occasionally & 69 \\
\hline & Sometimes & 17 \\
\hline & Frequently & 0 \\
\hline
\end{tabular}




\subsection{Item Selection by Initial Reliability Verification and Item Analysis}

First, the reliability of the response results was examined and proceeded to item analysis. With the overall Cronbach's $\alpha$ coefficient $=0.915$, the Cronbach's $\alpha$ coefficient between each factor $=0.912$ to 0.917 , and the Cronbach's $\alpha$ coefficient ( 0.7 to 0.8 or more), internal consistency was confirmed.

Following these analyses, an item analysis was performed. Analysis of the ceiling effect and the floor effect showed no ceiling effect was found, but floor effect was found in 2 items of RTBs in daily life and 14 items of RTBs in medication, which were excluded. Regarding the peakedness and skewness, items with an absolute value exceeding 1.5 were excluded based on the method of Tsuda et al. Two items were applicable, but these were the same as the items for which the floor effect was found, so no more items were excluded. In the GP analysis, 3 items of RTBs in daily life and 2 items of RTBs in medication were included.

Next, I-T analysis was performed. As a result, 9 items of RTBs in daily life and 2 items of RTBs in medication were applicable, and 7 items of RTB in daily life were newly excluded except for duplicate items.

Accordingly, the item analysis excluded 12 items of RTBs in daily life and 16 items of RTBs in medication, and finally 9 items of attributes, 20 items of RBTs in daily life, and 34 items of RTBs in medication by the nurse were selected. A total of 53 items were included in the factor analysis.

\subsection{Verification of Construct Validity by Factor Analysis}

To select the factor structure and items of the question items for the 20 items of RTBs in daily life and the 34 items of RTBs in medication extracted by the item analysis, the exploratory factor analysis using the maximum likelihood method and the Promax rotation was performed for each question item.

1) Factor analysis of RTB items in daily life

In the initial solution, the Kaiser-Meyer-Olkin test yielded a measure of sample validity with 0.737 , and the Bartlett sphere test yielded a significant value with $\mathrm{P}<0.001$. The difference in the change in eigenvalues was 1.798, 0.038, $0.321,0.148,0.045$, and 0.124 , which corresponded to the cumulative percentage (percentage of total variance) of $17.359,25.727,33.903,40.472$, and 46.302 , respectively. Considering the possibility of interpretation and the cumulative percentage, the four factors were considered to be appropriate. Therefore, assuming four factors, factor analysis was repeated until sufficient commonality and loading at 0.35 or more for any of the factors were shown. As a result, 4 factors and 12 items could be extracted, and the factor analysis was completed (Table 2). The extracted factors and items are as follows.

The first factor included "I may make a dash for the train" and "When walking, I will cross the road even at the red light if no cars are coming", and the items that represent the content related to the violation of traffic rules showed high loading value. Therefore, this was named the [Non-compliance with traffic 
Table 2. Results of factor analysis of RTBs in daily life.

\begin{tabular}{|c|c|c|c|c|c|c|}
\hline & Item & $\begin{array}{c}\text { Factor } \\
1\end{array}$ & $\begin{array}{c}\text { Factor } \\
2\end{array}$ & $\begin{array}{c}\text { Factor } \\
3\end{array}$ & $\begin{array}{c}\text { Factor } \\
4\end{array}$ & $\begin{array}{l}a \\
\text { coefficient }\end{array}$ \\
\hline \multirow[t]{5}{*}{ Factor 1} & Non-compliance with traffic rules & & & & & \\
\hline & A22: I may make a dash for the train & 0.628 & 0.112 & 0.041 & -0.026 & 0.868 \\
\hline & $\begin{array}{l}\text { A21: When walking, I will cross the road even at the red } \\
\text { light if there are no cars coming }\end{array}$ & 0.540 & -0.034 & -0.123 & 0.015 & 0.869 \\
\hline & $\begin{array}{l}\text { A6: I use my mobile phone while walking on the station } \\
\text { platform }\end{array}$ & 0.519 & -0.148 & 0.023 & -0.050 & 0.871 \\
\hline & $\begin{array}{l}\text { A18: When I'm in a hurry, I cross through an intersection } \\
\text { even if the yellow traffic light is blinking }\end{array}$ & 0.497 & 0.007 & 0.101 & 0.093 & 0.868 \\
\hline \multirow[t]{5}{*}{ Factor 2} & Preliminary action for safety confirmation & & & & & \\
\hline & $\begin{array}{l}\text { A29: I'm worried about whether the building is safe against } \\
\text { disasters when choosing a house }\end{array}$ & -0.023 & 0.650 & 0.118 & -0.090 & 0.871 \\
\hline & A19: When an unexpected event occurs, I calmly judge and act & 0.125 & 0.510 & -0.202 & 0.129 & 0.869 \\
\hline & A20: I check the evacuation exit when staying at a hotel or inn & -0.181 & 0.489 & -0.032 & 0.093 & 0.871 \\
\hline & A28: I act cautiously in anything & 0.035 & 0.393 & 0.026 & -0.250 & 0.868 \\
\hline \multirow[t]{3}{*}{ Factor 3} & Behavior affected by people & & & & & \\
\hline & A16: When a senior asks for a job, I may put off priorities & 0.018 & 0.074 & 0.765 & 0.035 & 0.868 \\
\hline & $\begin{array}{l}\text { A15: Even if there is a doubt about the instructions given by } \\
\text { the seniors, I sometimes do not confirm their intention }\end{array}$ & 0.005 & -0.148 & 0.552 & 0.026 & 0.866 \\
\hline \multirow[t]{3}{*}{ Factor 4} & Optimistic idea & & & & & \\
\hline & A3: I am optimistic about the future & -0.089 & -0.036 & 0.040 & 0.683 & 0.870 \\
\hline & A1: I often think that it will be alright & 0.123 & 0.074 & 0.025 & 0.554 & 0.868 \\
\hline
\end{tabular}

Factor extraction method: Maximum likelihood method. Rotation method: Promax method with Kaiser normalization. Factor loading of 0.35 or more is shown in bold.

\begin{tabular}{|c|c|c|c|c|}
\hline \multicolumn{5}{|c|}{ Factor correlation matrix } \\
\hline Factor & 1 & 2 & 3 & 4 \\
\hline 1 & 1.000 & & & \\
\hline 2 & -0.177 & 1.000 & & \\
\hline 3 & 0.143 & -0.204 & 1.000 & \\
\hline 4 & 0.096 & -0.142 & 0.000 & 1.000 \\
\hline
\end{tabular}

rules] factor.

The second factor included "I'm worried about whether the building is safe against disasters when choosing a house", "When an unexpected event occurs, I calmly judge and act", and "I check the evacuation exit when staying at a hotel or inn", and the items that represent the preliminary action for safety confirmation showed high loading value. Therefore, this was named the [Preliminary action for safety confirmation] factor. 
The third factor included "When a senior asks for a job, I may put off priorities" and "Even if there is a doubt about the instructions given by the seniors, I sometimes do not confirm their intention", and the items that represent behaviors affected by relationships with people such as seniors showed high loading value. Therefore, this was named the [Behavior affected by people] factor.

The fourth factor included "I am optimistic about the future" and "I often think that it will be alright", and the items that represent the content of optimistic thinking showed high loading value. Therefore, this was named the [Optimistic idea] factor.

The cumulative contribution rate of the four factors was $56.756 \%$, the factor loading was also sufficient, and the correlation of each factor showed less than 0.70 .

Confirmatory factor analysis was then performed to examine the goodness of fit between the data and the model. The analysis was performed using a model that assumed the items of each of the four factors were affected and all the factors correlated. As a result, the goodness-of-fit index indicated fit of the model with chi-square value $=181.612, \mathrm{GFI}=0.952, \mathrm{AGFI}=0.922, \mathrm{CFI}=0.852$, and RMSEA $=0.069(\mathrm{P}=0.000)$ (Figure 2).

Especially, the correlation value of [Preliminary action for safety confirmation] with [Optimistic idea], [Non-compliance with traffic rules], and [Behavior affected by people] were $r=-0.46, r=-0.40$, and $r=-0.26$, respectively, all of which exhibited negative values $(\mathrm{P}<0.001)$. In addition, weak positive correlation was found between [Non-compliance with traffic rules] and [Optimistic idea] $(r=0.25 ; \mathrm{P}=0.002)$ and [Non-compliance with traffic rules] and [Behavior

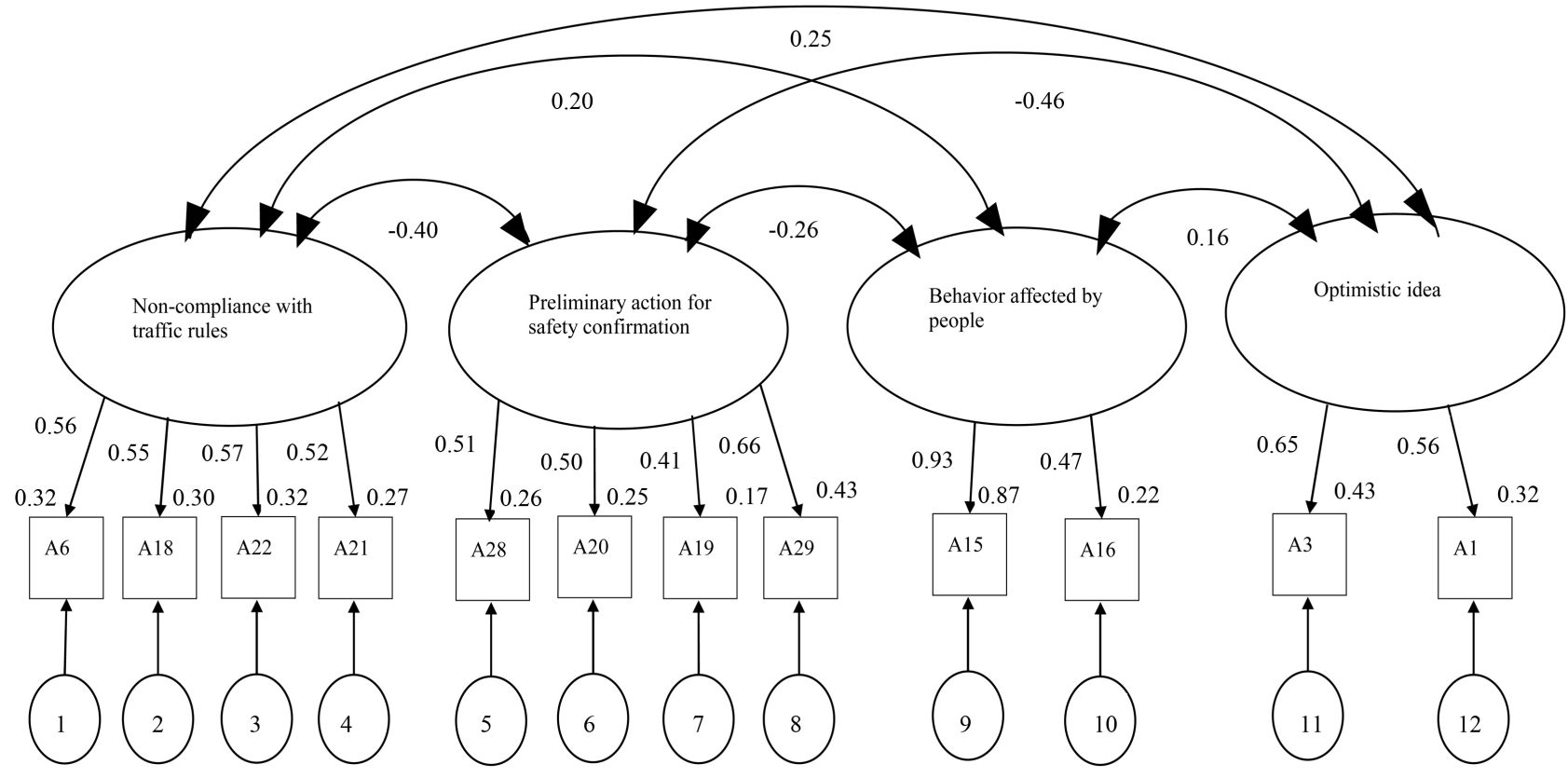

Chi-square test $=37.735$ Degrees of freedom $=19 \mathrm{P}$ value $=0.006$ GFI $=0.984$ AGFI $=0.969$ CFI $=0.980$ RMSEA $=0.041 \quad(\mathrm{P}<0.001)$

Figure 2. Results of confirmatory factor analysis of RTB model of daily life. 
affected by people] $(\mathrm{r}=0.20 ; \mathrm{P}<0.001)$. The lowest correlation value was found between [Behavior affected by people] and [Optimistic idea] $(\mathrm{r}=0.16 ; \mathrm{P}=0.014)$ showing no correlation.

\section{2) Factor analysis of RTB items in medication}

In the initial solution, the Kaiser-Meyer-Olkin test yielded a measure of sample validity with 0.954 , and the Bartlett sphere test yielded a significant value with $\mathrm{P}<0.001$. The differences in the changes in the eigenvalues were 10.04, $0.449,0.094,0.174,0.117$, and 0.050 , and the cumulative percentages (percentage of the total variance) were $34.854,40.286,44.398,48.233$, and 51.557. Considering the possibility of interpretation and the cumulative percentage, the four factors were appropriate. Therefore, assuming 4 factors, the factor analysis was repeated by the same method as above. Finally, 20 items could be extracted, and the factor analysis was completed (Table 3 ). The items are as follows.

Regarding the first factor, items representing the content of incomplete confirmation behavior depending on the situation, such as "I have omitted the confirmation $6 \mathrm{R}$ because I could not administer at the scheduled time" and "I have omitted the confirmation of the medication $6 \mathrm{R}$ because I kept the patient waiting", showed high loading value. Thus, the first factor was named the [Insufficient confirmation depending on the situation] factor.

Regarding the second factor, items representing behaviors that are not confirmed while recognizing, such as "I have received instructions without confirming the prescription of the drug" and "I have left it as it is, even though I felt something was wrong with the prescription", showed high loading value. Thus, the second factor was named the [Unconfirmed behavior while recognizing] factor.

Regarding the third factor, items representing erroneous behavior due to the presence of the patient and its involvement, such as "I have not performed dropping adjustment because I was impatient due to overlapped drip exchanges of multiple patients" and "I have vaguely confirmed the infusion because the work was interrupted due to a conversation with the patient and family", showed high loading value. Thus, the third factor was named the [Incorrect response due to human impact] factor.

Regarding the fourth factor, items representing the content related to multiple tasks, such as "I have missed scheduled medication due to complicated work" and "I have forgotten to administer scheduled medicines during multiple tasks", showed high loading value. Thus, the fourth factor was named the [Missing due to multiple tasks] factor. The cumulative contribution rate of the four factors was 56.706, and the factor loading was also sufficient, and the estimated value of the correlation of each factor was less than 0.70 .

Confirmatory factor analysis was then performed to examine the goodness of fit between the data and the model. The analysis was performed using a model that assumed the items of each of the four factors were affected and all the factors correlated. As a result, the goodness-of-fit index indicated fit of the model 
Table 3. Results of factor analysis of RTBs in medication.

\begin{tabular}{|c|c|c|c|c|c|c|}
\hline & Item & Factor 1 & Factor 2 & Factor 3 & Factor 4 & a coefficient \\
\hline \multirow[t]{7}{*}{ Factor 1} & Insufficient confirmation depending on the situation & & & & & \\
\hline & $\begin{array}{l}\text { B19: I have omitted the confirmation } 6 \mathrm{R} \text { because I could } \\
\text { not administer at the scheduled time }\end{array}$ & 0.867 & -0.001 & -0.044 & -0.039 & 0.861 \\
\hline & $\begin{array}{l}\text { B29: I have omitted the confirmation of the medication } \\
6 \mathrm{R} \text { because I kept the patient waiting }\end{array}$ & 0.735 & -0.111 & 0.171 & -0.022 & 0.861 \\
\hline & $\begin{array}{l}\text { B13: In an emergency, I have not been able to } \\
\text { confirm } 6 \mathrm{R} \text { of the drug }\end{array}$ & 0.717 & 0.104 & -0.194 & 0.115 & 0.861 \\
\hline & $\begin{array}{l}\text { B9: I have omitted } 6 \mathrm{R} \text { when other people such as } \\
\text { pharmacists and nurses are preparing }\end{array}$ & 0.708 & 0.089 & -0.044 & -0.001 & 0.861 \\
\hline & $\begin{array}{l}\text { B32: I have not been able to calmly confirm the } \\
\text { oral administration }\end{array}$ & 0.583 & -0.053 & 0.203 & 0.019 & 0.862 \\
\hline & $\begin{array}{l}\text { B31: I have missed the confirmation when I am } \\
\text { impatient with the first drug administration and so on }\end{array}$ & 0.528 & -0.016 & 0.195 & 0.004 & 0.862 \\
\hline \multirow[t]{8}{*}{ Factor 2} & \multicolumn{3}{|l|}{ Unconfirmed behavior while recognizing } & & & \\
\hline & $\begin{array}{l}\text { B2: I have received instructions without } \\
\text { confirming the prescription of the drug }\end{array}$ & 0.004 & 0.756 & -0.018 & -0.081 & 0.864 \\
\hline & $\begin{array}{l}\text { B4: Collation of medication instruction } \\
\text { comments has been missed }\end{array}$ & 0.085 & 0.621 & -0.032 & 0.018 & 0.863 \\
\hline & $\begin{array}{l}\text { B3: I have not confirmed leftover drugs when } \\
\text { receiving instructions such as additional drugs }\end{array}$ & 0.138 & 0.605 & -0.015 & -0.043 & 0.863 \\
\hline & B6: I have forgotten to discontinue oral administration & -0.149 & 0.564 & 0.037 & 0.113 & 0.866 \\
\hline & $\begin{array}{l}\text { B1: I have judged that the oral instruction is the } \\
\text { same as before and received it by mistake }\end{array}$ & -0.077 & 0.563 & 0.064 & 0.025 & 0.865 \\
\hline & $\begin{array}{l}\text { B7: I have left it as it is, even though I felt something } \\
\text { was wrong with the prescription }\end{array}$ & 0.143 & 0.414 & 0.057 & 0.006 & 0.864 \\
\hline & $\begin{array}{l}\text { B10: I have neglected to confirm the drugs } \\
\text { brought by the patient }\end{array}$ & 0.082 & 0.385 & 0.090 & -0.020 & 0.865 \\
\hline \multirow[t]{4}{*}{ Factor 3} & \multicolumn{4}{|l|}{ Incorrect response due to human impact } & & \\
\hline & $\begin{array}{l}\text { B38: I have not performed dropping adjustment } \\
\text { because I was impatient due to overlapped drip } \\
\text { exchanges of multiple patients }\end{array}$ & -0.031 & -0.068 & 0.733 & 0.056 & 0.864 \\
\hline & $\begin{array}{l}\text { B40: I have vaguely confirmed the infusion because the } \\
\text { work was interrupted due to a conversation with the } \\
\text { patient and family }\end{array}$ & 0.056 & 0.037 & 0.647 & 0.019 & 0.863 \\
\hline & $\begin{array}{l}\text { B39: I have missed the confirmation of the operation } \\
\text { status of IV drip including syringe pump }\end{array}$ & 0.073 & 0.064 & 0.573 & -0.062 & 0.864 \\
\hline
\end{tabular}




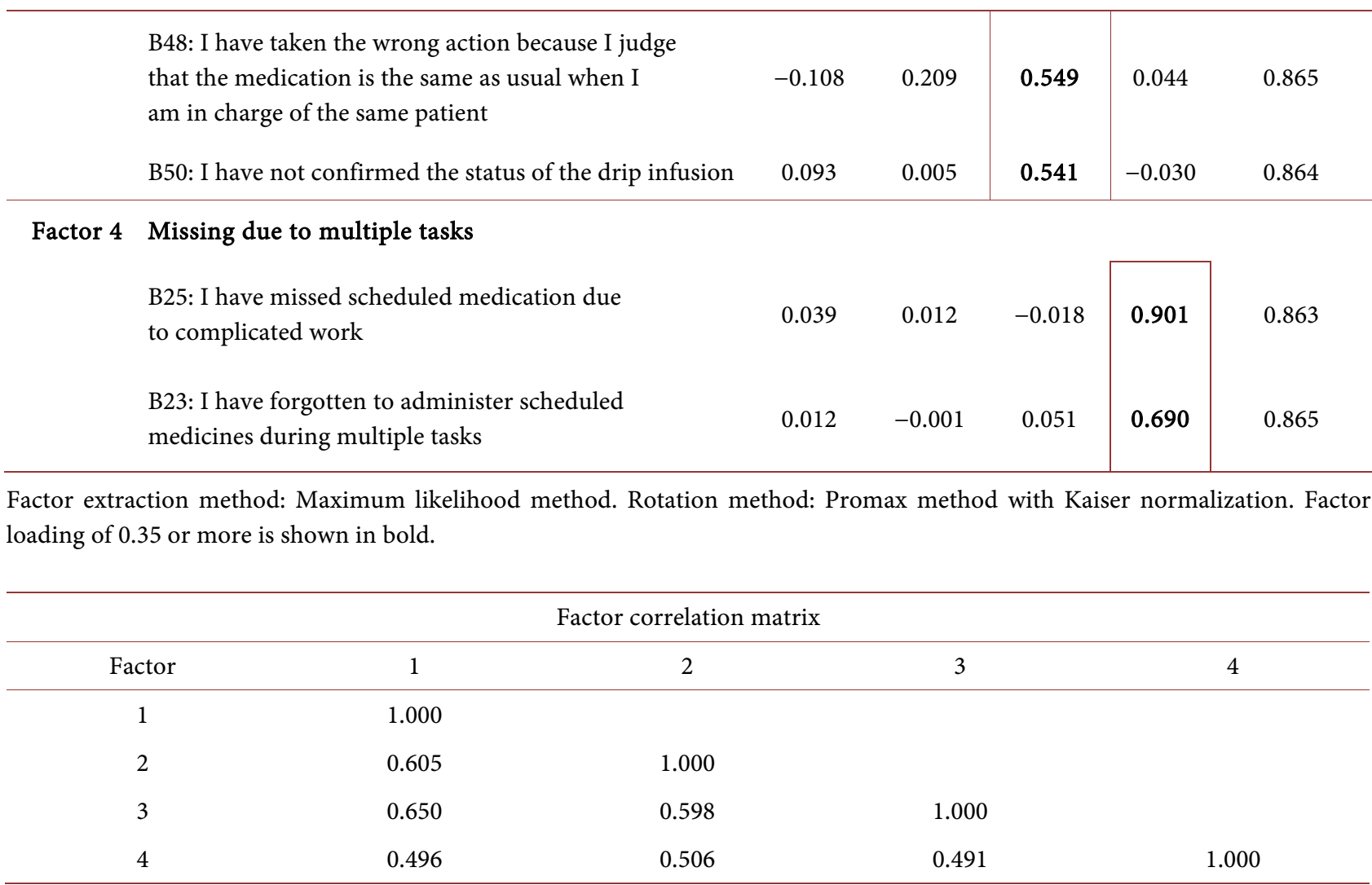

with chi-square value $=311.172, \mathrm{GFI}=0.949, \mathrm{AGFI}=0.935, \mathrm{CFI}=0.966$, and RMSEA $=0.039(\mathrm{P}=0.000)$. Especially, the correlation value of [Insufficient confirmation depending on the situation] with [Incorrect response due to human impact] was the highest with $r=0.71$, followed by correlation of [Insufficient confirmation depending on the situation] with [Unconfirmed behavior while recognizing] with $r=0.68$. The lowest value was $r=0.54$ for correlation of [Missing due to multiple tasks] with [Incorrect response due to human impact] ( $\mathrm{P}<$ 0.001) (Figure 3).

3) Examination of RTB factors in daily life and RTB factors in medication using a multi-index model

The score of each factor of RTBs in daily life and RTBs in medication extracted by exploratory factor analysis were used as observation variables, and the tendencies of RTBs in daily life and RTBs in medication were used as latent variables, and a causal relationship among the latent variables was confirmed. As a result, the goodness-of-fit index indicated fit of the model with chi-square value $=$ $37.735, \mathrm{GFI}=0.984$, AGFI $=0.969, \mathrm{CFI}=0.980$, and $\mathrm{RMSEA}=0.041(\mathrm{P}=$ $0.006)$.

In addition, a strong correlation $(\mathrm{r}=0.63)$ was found in the causal relationship among latent variables $(\mathrm{P}<0.001)$. Thus, a relationship between the tendency of RTBs in daily life and the tendency of RTBs in medication was found (Figure 4). 


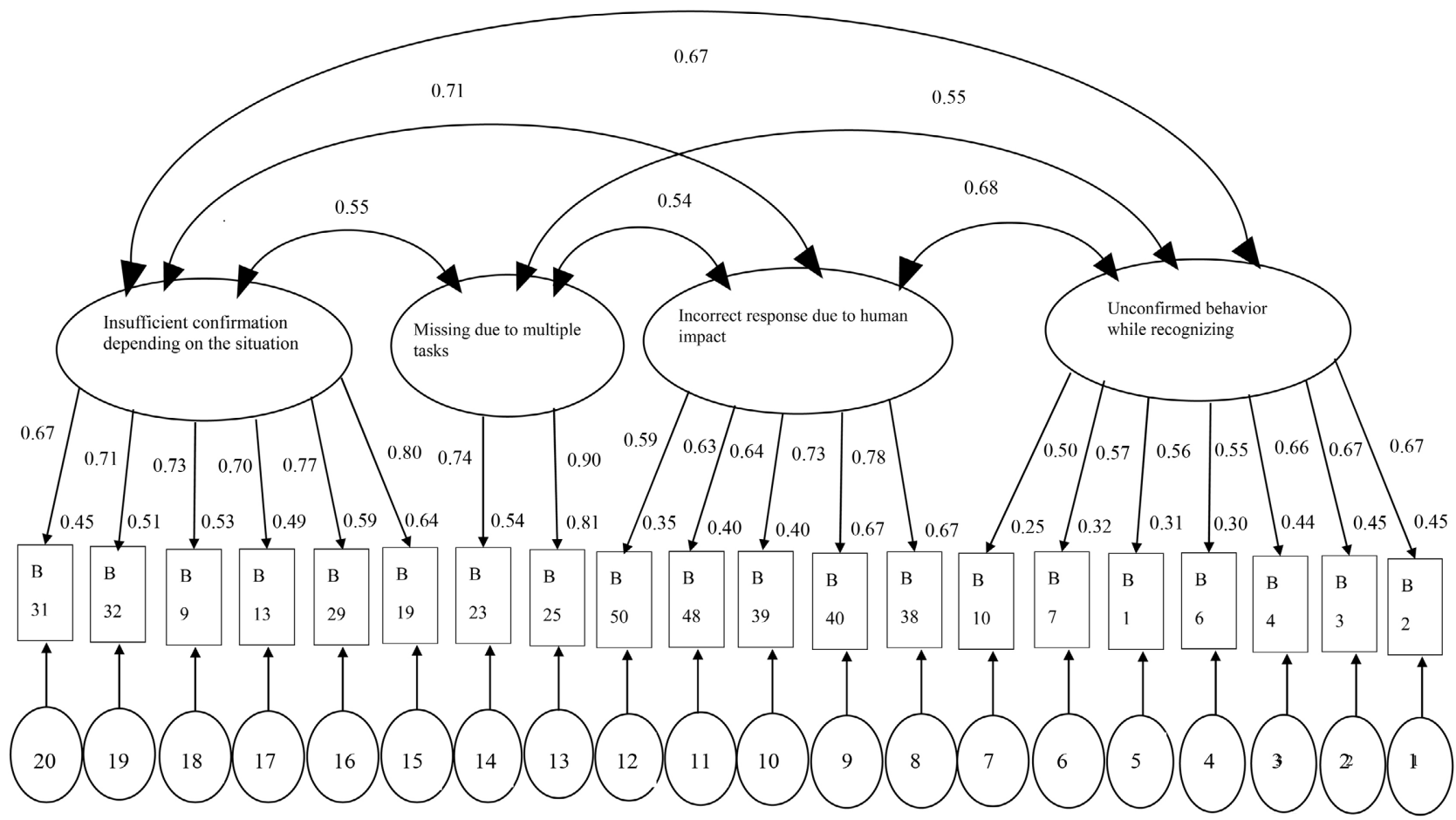

Chi-square test $=37.735$ Degrees of freedom $=19$ P value $=0.006$ GFI $=0.984$ AGFI $=0.969$ CFI $=0.980$ RMSEA $=0.041 \quad(P<0.001)$

Figure 3. Confirmatory factor analysis of RTB model in daily life and RTB model in medication.

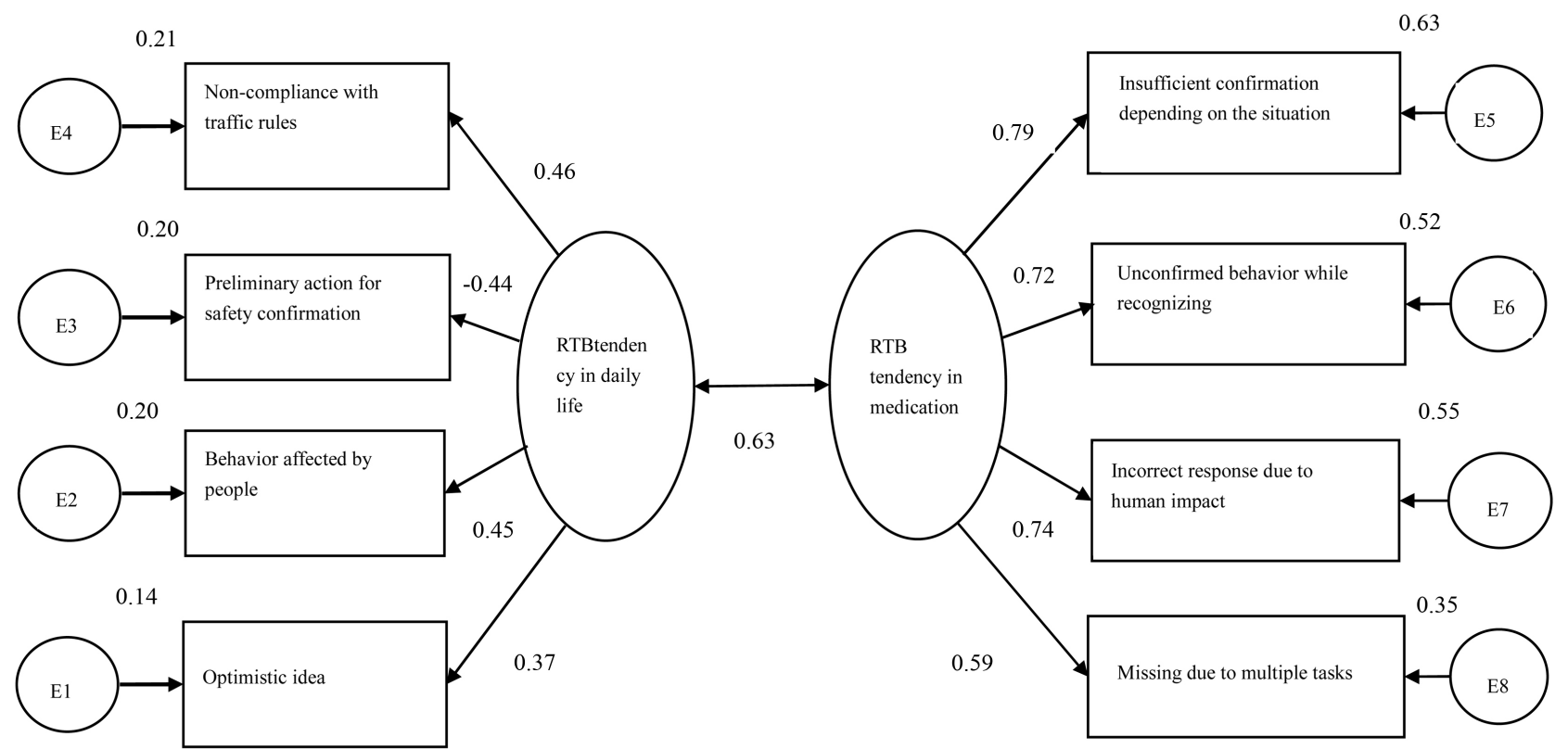

Chi-square test $=37.735$ Degrees of freedom $=19 \mathrm{P}$ value $=0.006$ GFI $=0.984$ AGFI $=0.969$ CFI $=0.980$ RMSEA $=0.041 \quad(\mathrm{P}<0.001)$

Figure 4. Confirmatory factor analysis of RTB model in daily life and RTB model in medication.

4) Examination of convergent validity and discriminant validity using a multi-index model

Regarding convergent validity and discriminant validity, association between RTBs in medication and medical accidents was predicted, and then association 
between RTBs in medication and incident/accident experiences was examined. The goodness-of-fit index indicated fit of the model with chi-square value = $76.375, \mathrm{GFI}=0.974, \mathrm{AGFI}=0.959, \mathrm{CFI}=0.960$, and $\mathrm{RMSEA}=0.046(\mathrm{P}<0.001)$ (Figure 5).

In the case of incident experience, correlation with [behavior affected by people] was not significant, but correlation with total items of RTBs and other factor items were significant. On the other hand, in the case of accident experience, a significant correlation with all items of RTBs in daily life was not found, but a significant correlation with items of RTBs in medication and total items of RTBs was found. Thus, convergent validity was noted (Figure 5).

Regarding examination of discriminant validity, three items of educational background, years of experience, and experience as a member of the medical safety measures committee were predicted not to be the cause and were included. As a result, the goodness-of-fit index indicated fit of the model with a chi-square value $=217.398, \mathrm{GFI}=0.934, \mathrm{AGFI}=0.899, \mathrm{CFI}=0.841$, and RMSEA $=0.083$ (Figure 6).

The correlation of RTBs in medication with school-age and years of experience as a nurse showed low values ranging from $r=0.00$ to 0.03 , and no significant correlation was found between the 3 items and all factors of RTBs in daily

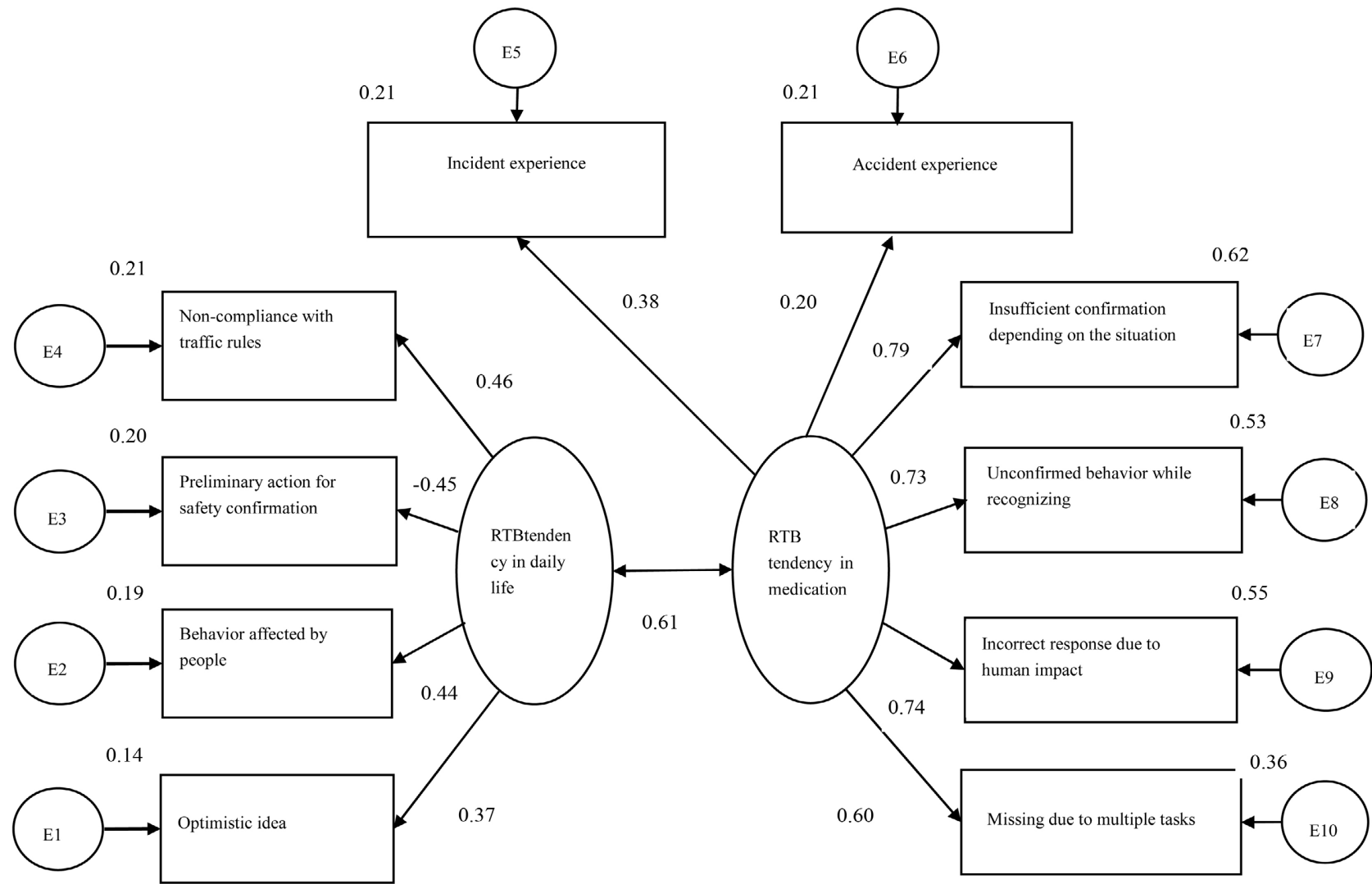

Chi-square test $=76.375$ Degrees of freedom $=34 \mathrm{P}$ value $=0.000 \mathrm{GFI}=0.974 \mathrm{AGFI}=0.959 \mathrm{CFI}=0.960 \mathrm{RMSEA}=0.046 \quad(\mathrm{P}<0.001)$

Figure 5. Each RTB model and results of confirmatory factor analysis of incident/accident. 


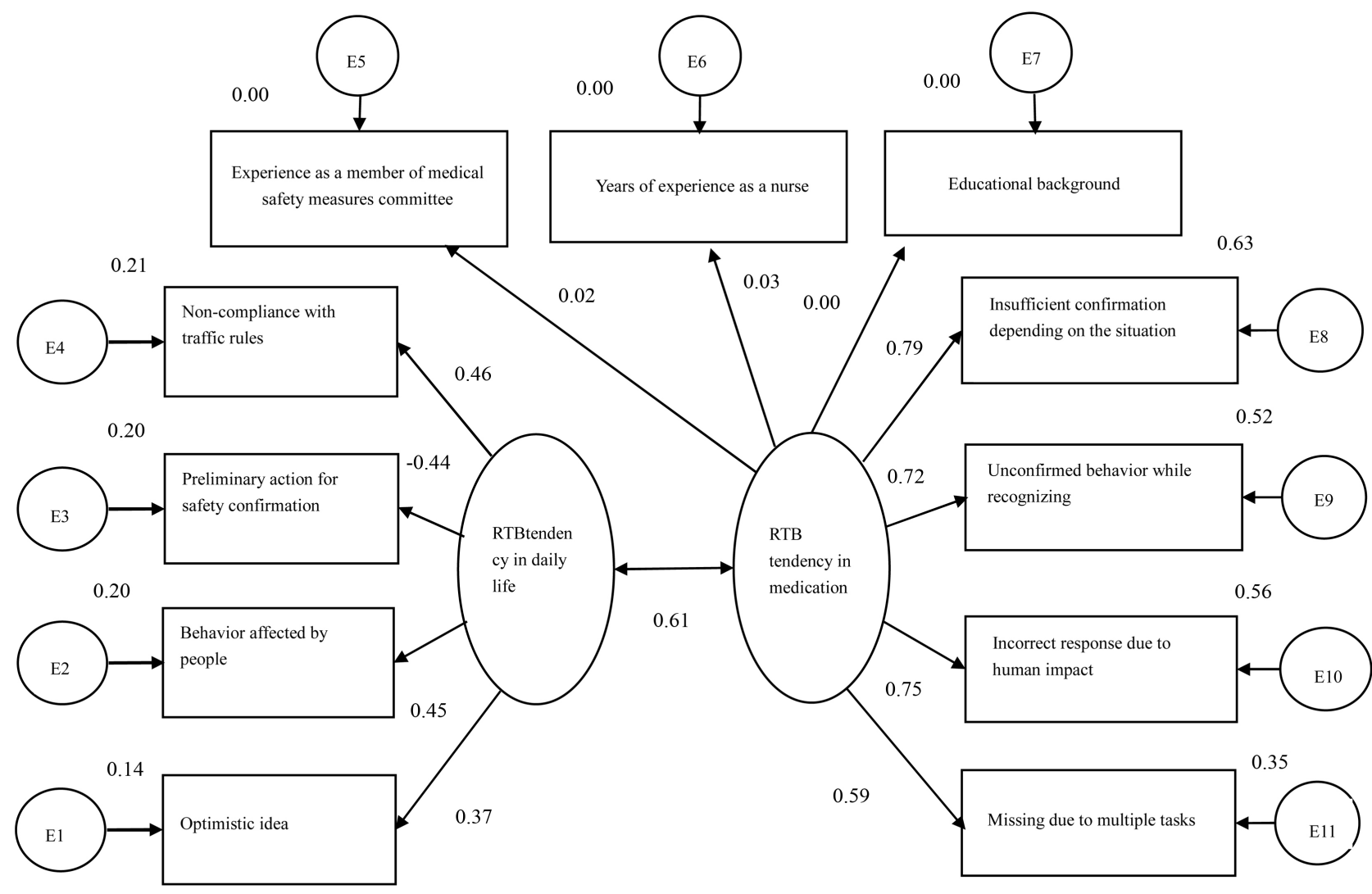

Chi-square test $=217.398$ Degrees of freedom $=43 \mathrm{P}$ value $=0.000 \mathrm{GFI}=0.934$ AGFI $=0.899 \mathrm{CFI}=0.841$ RMSEA $=0.083$

Figure 6. Discriminant validity of RTBs in daily life and RTBs in medication.

life and RTBs in medication. This confirmed the discriminant validity.

\subsection{Examination of Internal Consistency}

Based on the results of factor analysis, internal consistency was verified. The overall Cronbach's $\alpha$ coefficient (0.888), the Cronbach's $\alpha$ coefficient between each factor ( 0.861 to 0.871 ), and the Cronbach's $\alpha$ coefficient ( 0.7 to 0.8 or more) showed internal consistency.

\subsection{Correlation between RTBs in Medication and Incident/Accident Experiences and Examination of Evaluation Criteria}

Since RTBs in medication were predicted to be associated with medical accidents, the association with incident/accident experiences was examined. Those with higher total scores of RBTs were predicted to have more incident/accident experiences. Multiple regression analysis was conducted using the risk-taking total scores as dependent variables and the incident/accident scores as independent variables, and resultant data were analyzed using Pearson's correlation coefficient. The significance probability was $P=0.000$ at $r=0.306$ for correlation of total scores of RBTs with incident experience, and the significance probability 
was $\mathrm{P}=0.000$ at $\mathrm{r}=0.144$ for correlation of total scores of RBTs with accident experience.

Next, the evaluation criteria for RTBs were examined. The total scores obtained from answers to the extracted RTB question items were calculated, the target data was divided into four equal groups, and these were compared with incident/accident experiences. Kruskal-Wallis test was conducted, and the significance level was set at $\mathrm{p}<0.01$. As a result of the test, the self-evaluation criteria based on the total scores of RTBs were up to 66 points (RTB tendency is weak), $67-72$ points (RTB tendency is a little weak), 73 - 79 points (RTB tendency is a little strong) and 80 or higher points (RTB tendency is strong). The significance probability was $\mathrm{P}<0.000$ for the incident experience and $\mathrm{P}=0.003$ for the accident experience.

\section{Discussion}

The purpose of this study was to develop a self-assessment questionnaire for nurses' RTBs on medication. Therefore, we conducted a questionnaire survey of nurses nationwide and verified the obtained data by exploratory factor analysis and confirmatory factor analysis. In addition, in the analyses, not all the data were collected at once, but the daily life part and the medication part were separated. As a result, individual tendencies in daily life could lead to meaningful results in examining the relationship with the medication part.

As for the self-evaluation question items of RTBs, 4 factors and 12 sub-items could be extracted for RTBs in daily life, and 4 factors and 20 sub-items could be extracted for RTBs in medication. We discuss the results as follows.

\subsection{Attribute Characteristics}

In this study, to evaluate nurses' RTBs, the questions were divided into three parts and examined for the attributes and sub-items of RTBs in daily life and RTBs in medication, respectively.

As a characteristic of the attributes, many nurses with 0 to 2 years of experience and many nurses assigned to the current department for 0 to 2 years were included. According to the Project to Collect Medical Near-miss/Adverse Event Information Annual Report of the Japan Council for Quality Health Care, as a characteristic of medical accidents by nurses, shorter years of experience and shorter years after assignment to the department have been pointed out. It can be said that the subjects in this study were also under the same conditions. In addition, concerning the incident experience, 458 nurses $(78.1 \%)$ answered "occasionally", "sometimes", and "frequently", which occupied more than 3/4. To prevent medical accidents, it is necessary to pay attention to the years of experience and the years of assignment.

\subsection{Construct Validity}

In this study, the results of the questionnaire prepared in the previous study 
were divided into RTB items in daily life and RTB items in medication, and exploratory factor analysis and confirmatory factor analysis were performed step by step.

In the exploratory factor analysis, 4 factors could be extracted for each, resulting in a total of 32 items for 8 factors. The cumulative contribution rate and the factor loading showed sufficient values, and the factor correlation was less than 0.70 . Thus, each factor is found to be separated.

As for the RTBs in daily life, four factors were extracted: [Non-compliance with traffic rules], [Preliminary action for safety confirmation], [Behavior affected by people], and [Optimistic idea]. These factors correspond to the 4 categories [Situational factor], [Personality factor], [Recognition factors], and [behavioral skills factor] proposed by Imura [15].

As for the RTBs in medication, four factors were extracted: [Insufficient confirmation depending on the situation], [Unconfirmed behavior while recognizing], [Incorrect response due to human impact], and [Missing due to multiple tasks]. These factors are thought to correspond to [Omission of verification process due to multiple tasks], [Ambiguous response to instructions], and [Omission due to circumstances such as refraining from patients] as proposed by previous studies.

As a result of the confirmatory factor analysis, it was judged that the fit of the model was good, and the model was valid. However, the $\chi$-square test resulted in the rejection of the null hypothesis. This might be because the number of subjects in this study was as many as $\mathbf{5 0 0}$ or more and might affect the results. It has been reported that in confirmatory factor analysis, a large sample size affects the test results [19].

Regarding the RTBs in daily life, the factor scores of "Non-compliance with traffic rules" were high. Moriizumi studied the relationship between RTBs and traffic offenders. It has been suggested there is a link between risk tendency and traffic violations, and especially the higher the tendency to take risks depending on the situation, the more likely it is to have a traffic accident, leading to recurrence of driving accidents within two years [12] [13]. In the future, it will be necessary to consider RTBs in nurses' daily life, the occurrence and timing of medical accidents, and suppressors.

Regarding the RTBs in medication, 4 factors and 20 sub-items could be extracted. Each factor loading showed a high loading value. In particular, the three factors [Insufficient confirmation depending on the situation], [Incorrect response due to human impact], and [Unconfirmed behavior while recognizing] showed high values with $r=0.70$ or higher. There have been several studies suggesting that the addition of time factors as an influential factor for RTBs to individual tendencies may affect RTBs, and reasonable results are, therefore, thought to be obtained [4] [10] [20] [21].

In the causal relationship between RTBs in daily life and RTBs in medication using a multi-index model, the correlation coefficient was as high as $\mathrm{r}=0.68$. This result is consistent with the results of Fujii who investigated RTBs and sug- 
gested the relationship between behaviors in daily life and nursing situations [9].

Fujii clarified that as a characteristic of RTBs, the tendency of RTBs in traffic scenes and daily situations affects the risk-taking probability in nursing situations. She also focused on the risk assessment of nurses, suggesting that if nurses receive a high mark for risk assessment in nursing practice, they may not take risk-taking behaviors [9].

Individuals might recognize and avoid risky situations in their daily lives or might not avoid them [22]. There are many risks in clinical settings, and nurses always prioritize risk-avoiding behaviors. However, there are certainly some differences in the way they should be, depending on individual judgments and ways of thinking, which might affect the daily tendencies of individuals. Ueichi (1998) showed that RTBs are characterized by scene consistency, inducing factors, and inhibitory factors and that the group that selects risky behaviors shows personal tendencies such as behaving riskily in other scenes. He also mentioned the inhibitory factors [23].

Since this study does not include survey items for behaviors that suppress RTBs, it may be necessary to consider these suppressors in future studies.

\subsection{Examination of the Reliability}

A certain degree of internal consistency was found based on the Cronbach's $\alpha$ coefficients for the entire questionnaire and each factor.

The Cronbach's $\alpha$ coefficient for the entire questionnaire showed a high value of 0.888 . Since it is said that internal consistency is high when the value of Cronbach's $\alpha$ is 0.7 or more, the questionnaire developed in this study is considered to have high internal consistency and reliable [24].

Thus, we believe that in this study, a valid and reliable questionnaire with the elements of nurses' RTBs in medication could be developed. In addition, the development of this questionnaire will enable individual nurses to be aware of their RTB tendencies, which may help prevent accidents.

\subsection{Limitations of the Study and Challenges for the Future}

In this study, we conducted a survey of nurses involved in medication, developed a questionnaire that enables self-evaluation of RTB tendencies, and could confirm its reliability and validity. It was clarified that RTBs in daily life and RTBs in medication were related to influential factors such as people, time, environment, and personal factors. However, since this research method is based on a questionnaire survey, it is not possible to verify the relationship between actual behaviors and RTBs, which is considered to be one of the limitations of the study.

As for challenges for the future, it is necessary for nurses themselves to understand their tendencies, raise awareness of medical accident prevention, and take measures. In addition, in a medical setting, it is predicted that situational factors such as time pressure and human impact will be inducing factors for RTBs. This 
self-assessment questionnaire did not include survey items to ask about characteristics of the subject's assigned place and time pressure. We think it is necessary to consider the contents of the survey in the future.

\section{Conclusions}

This study aimed at developing a self-assessment questionnaire for nurses' RTBs. A draft of the sub-items of the questions regarding RTBs was prepared based on literature review and important case information included in the Project to Collect Medical Near-miss/Adverse Event Information Annual Report. A questionnaire survey was then conducted, and the results of valid responses obtained from 586 nurses were analyzed to verify their reliability and validity.

Regarding the RTBs in daily life, 4 factors such as [Non-compliance with traffic rules], [Preliminary action for safety confirmation], [Behavior affected by people], and [Optimistic idea] and 12 sub-items, and regarding the RTBs in medication, 4 factors such as [Insufficient confirmation depending on the situation], [Unconfirmed behavior while recognizing], [Incorrect response due to human impact], and [Missing due to multiple tasks] and 20 sub-items could be extracted. Confirmatory factor analysis verified the validity of the factor model, confirmed the suitability of the model, and further confirmed the results supporting the validity of the construct composed of 8 factors. A strong correlation $(r=0.63)$ was found between RTBs in daily life and RTBs in medication.

A certain degree of internal consistency was found based on the entire RTB questionnaire and the Cronbach's $\alpha$ coefficient for each factor.

\section{Acknowledgements}

We are deeply grateful to everyone who cooperated in this study. This study was submitted by adding a part of the doctoral dissertation submitted to the Graduate School of Osaka Medical and Pharmaceutical University.

\section{Conflicts of Interest}

The authors declare no conflicts of interest regarding the publication of this paper.

\section{References}

[1] Search on the Project to Collect Medical Near-Miss/Adverse Event Information 2010-2016 Annual Report of the Japan Council for Quality Health Care. https://www.med-safe.jp

[2] Soma, T. (2016) Latest Trends in Medical Safety-Learn from WHO Patient Safety Curriculum Guide: Multi-Professional Edition 2011. Physical Therapy, 43, 120-123.

[3] Sumai, S. (2012) Factor of Medical Accidents Associated with Nurses and Current Countermeasures. Bulletin of Faculty of Nursing of Chukyo Gakuin University, 2, 47-59.

[4] Yoshida, R. (2010) Risk-Taking Behavior in Nursing Practice and Related Factors. Journal of Japanese Society of Nursing Research, 35, 183-194. 
[5] Wada, K., Usui, S., Shinohara, K., Kanda, K., Nakamura, T., Murakami, Y., et al. (2012) Effects of the Task Cost and Risk Perception on Rule Violation Behavior. Journal of Science of Labor, 88, 1-12.

[6] Haga, S., Akatsuka, H., Kusugami, K. and Kanano, S. (1994) Analysis of Personal Differences and Factors in Risk-Taking Behaviors by Questionnaire Survey. Railway Technical Research Institute Report, No. 12, 19-22.

[7] Oshio, S. (2001) Development and Validation of a Risk-Taking Behavior Scale for Undergraduates (RIBS-U). Bulletin of the Graduate School of Education and Human Development. Psychology and Human Developmental Sciences, 48, 257-265.

[8] Matsuzaki, E. and Endo, E. (2004) Analysis of Risk-Taking Behaviors of Nursing Students: Critical Thinking Orientation and Relationship between Risk Tendency and Risk Rating. Journal of the Japan Academy of Nursing Administration and Policies, 8, 58-67.

[9] Fujii, M., Yonezawa, H. and Hasegawa, T. (2009) Factors Affecting Risk Assessment in Nursing Situations Where Falls May Be Expected. Journal of the Japan Academy of Nursing Administration and Policies, 12, 32-41.

[10] Adachi, Y., Yamaguchi, E., Matsumoto, T. and Usui, S. (2014) Psychological Factors in Nursing Violations by Students of a Nursing School and Risk Managers in a Hospital. Japanese Journal of Applied Psychology, 40, 23-35.

[11] Weber, U.E., Blais, A. and Betz, E.N. (2002) A Domain-Specific Risk-Attitude Scale. Journal of Behaivioral Decision Making, 15, 263-290.

[12] Moriizumi, S., Usui, S. and Nakai, H. (2010) Development of a Scale to Measure the Tendency of Risk-Taking Behavior and Testing Its Reliability and Validity: A preliminary Study. Journal of Science of Labor, 86, 127-138.

[13] Moriizumi, S. and Usui, S. (2011) Re-Examining the Reliability and Validity of the Scale to Measure the Tendency of Risk-Taking Behavior. Journal of Science of Labor, 87, 211-225.

[14] Imura, Y., Azuma, M. and Akazawa, C. (2020) Current Status of Nurses' Risk-Taking Behavior during Drug Administration: Analysis of Accident Reports by Text Mining. Nursing Journal of Osaka Aoyama University, 4, 1-10.

[15] Imura, Y. and Akazawa, C. (2020) Development of a Questionnaire about RiskTaking Behaviors among Nurses during Administration of Medication. Journal of Osaka Aoyama University, 13, 7-16.

[16] Tsuda, A., Shimomitsu, T., Odagiri, Y., Husima, A. and Tanaka, Y. (2012) Development of a New Stress Questionnaire "Comprehensive Health Check for Workers" (CHCW). Comprehensive Medicine, 2, 2-28.

[17] Murakami, Y. (2017) How to Make a Psychological Scale? Kitaooji Shobo Publishing, Kyoto.

[18] Toyoda, H. (2021) Covariance Structure Analysis. Tokyo Tosho, Tokyo, 18-19.

[19] Asano, M., Suzuki, N. and Kojima, T. (2005) Introductory Practice of Covariance Structure Analysis. Kodansha, Tokyo, 105-134.

[20] Thompson, C., Dalgleish, L., Bucknall, T., Estabrooks, C., Hutchinson, A.M., Fraser, K., de Vos, R., Binnekade, J., Barrett, G. and Saunders, J. (2008) The Effects of Time Pressure and Experience on Nurses' Risk Assessment Decisions: A Signal Detection Analysis. Nursing Research, 57, 302-311. https://doi.org/10.1097/01.NNR.0000313504.37970.f9

[21] Äyvaz, M.Y., Akyol, Y.E. and Demiral, M. (2019) Innovation in Nursing and Innovative Attitudes of Nurses. International Health Administration and Education (Sa- 
nitas Magisterium), 5, 52-59.

[22] Renge, K. (2000) Psychological Process of Risk-Taking Behaviors during Driving and Approach to Risk-Avoiding Behaviors. International Association of Traffic and Safety Sciences Research, 26, 12-22.

[23] Ueichi, H. and Kusumi, T. (1998) Effects of Personality/Cognitive/Situational Factors on Risk-Taking Behaviors. Psychological Studies, 69, 81-88.

[24] Oshio, A. (2008) Psychology and Survey Data Analysis Factor Analysis and Covariance Structure Analysis by SPAA and Amos. Tokyo Tosho, Tokyo, 143-150. 